\title{
"CLINICAL STUDY OF CLAVIEN-DINDO CLASSIFICATION TO ASSESS THE GRADES OF COMPLICATION AND FACTORS RESPONSIBLE IN CASES OF GASTROINTESTINAL PERFORATIONS IN A TERTIARY CARE CENTRE"
}

\section{Dr. Ankur Deshwali*}

\section{Dr. Rajesh Sharma}

\section{Resident ,General Surgery \& Sri Aurobindo medical college \&postgraduate} institute,indore,Madhya Pradesh india. * Corresponding Author

Proffesar \& Sri Aurobindo medical college \&postgraduate institute, indore, Madhya Pradesh india.

ABSTRACT INTRODUCTION: Perforation peritonitis is one of the most common surgical emergencies across the globe. Gastrointestinal perforations have very high morbidity and mortality rates, irrespective of the type of operative procedure performed. The Clavien-Dindo system is nowadays widely used for complications after surgery for grading adverse events (i.e. complications) which occur as a result of surgical procedures and has become the standard classification system for many surgical specialties for open as well as laparoscopic surgeries . In this study, an attempt is made to find out various preoperative and intra operative factors that may responsible for adverse outcome and to identify the best management that could decrease the complication rate with special reference to CLAVIEN-DINDO classification.

MATERIALS AND METHODS: We did an observational study of 60 perforation peritonitis patients admitted in Department of Surgery, Sri Aurobindo Medical College and Post Graduate Institute, Indore, M.P. between November 2017 to May 2019 (1 and l/2 Year) on the basis of Clavien-Dindo classification.All were studied with respect to clinical features, time of presentation, comorbid conditions, investigations, intervention done, operative findings and postoperative course and all the data was entered in preformed proforma

RESULTS: Total 60 patients of perforation peritonitis admitted and treated in the department, During the period of November 2017 to May 2019. End of the study concludes the following points:

- In my study, most of the cases were between age group 20-39(50\%). more common in males 41 (68.33\%).

who presented after 3 days from onset of symptoms 20 (33.33\%) all of them had complications $20(100 \%)$. P Value was $<0.001$ which is significant. In $16(26.6 \%)$ patient's comorbid conditions were present, out of them $12(75 \%)$ patients were haemodynamically unstable and $9(56.25 \%)$ patient expired.In $29(48.33 \%)$ patient size of perforation was more than $1 \mathrm{~cm}$ out of which complication observed in $28(96.55 \%)$ patient.. P Value was $<0.001$ which is significant. In $10(16.66 \%)$ patients multiple perforations were found out of which $09(90 \%)$ patients were unstable. Complication occurred in 09(90\%) patients . In this group $6(60 \%)$ patient expired. P Value was 0.001 which is significant. In $24(40 \%)$ patients more than 500 ml intraperitoneal collection was found, out of which complications developed in all 24(100\%) patients,. Chi Square Value was 42.8 and P Value was $<0.001$ which is significant.

Complication according to clavien -dindo classification 14 out of $60(23.33 \%)$ patients had no complications, 4 (6.66\%) had grade I complication, 5 (8.33\%) had grade II complications, 12 (20\%) had grade III complications, 11 (18.33\%) had grade IV complications, and 14 (23.33\%) had grade $\mathrm{V}$ complication rates .

CONCLUSION:Post-operative complications increase due to comorbid conditions, size and number of perforations and it also affects the outcome of the patient. It is observed that with the increase in contamination (intraperitoneal collection) morbidity increases.For the classification of complications, a new system is proposed by Clavien-Dindo which is very helpful during perforation surgery, it is used in all over the world and facilitates in comparisons or evaluation of various surgical . The new classification mainly focuses on the medical perspective, with a major emphasis on the risk, type of anaesthesia and procedures or therapy used to correct a complication. We therefore recommend the use of clavien-dindo classification of complications.

\section{KEYWORDS : Perforation Peritonitis, risk factors, complications, outcome, clavien-dindo classification of} complications.

\section{INTRODUCTION:}

Perforation peritonitis is one of the most common surgical emergencies across the globe. Gastrointestinal perforations have very high morbidity and mortality rates, irrespective of the type of operative procedure performed. The aim of the present study is to assess the complications and factors responsible for outcomes in cases of gastrointestinal perforations in a tertiary care centre and also to find out various determinants for safe outcomes in gastrointestinal perforation in terms of decreased morbidity and mortality and applying Clavien-Dindo classification for postoperative complications for evaluating the outcome.

The Clavien-Dindo system is nowadays widely used for complications after surgery for grading adverse events (i.e. complications) which occur as a result of surgical procedures and has become the standard classification system for many surgical specialties for open as well as laparoscopic surgeries.

Perforation peritonitis is one of the most common acute abdominal conditions in India because the disease mostly affects the middle and lower socio-economically class, patients comes to emergency department in septic shock (systemic inflammatory response syndrome [SIRS]) and multi organ dysfunction syndrome [MODS] in later stages of the conditions .As patients present late with septicemia, fluid and electrolyte derangements, shock, and/or systemic inflammatory response syndrome the management becomes quite challenging.

The combination of general care of patients, correction of fluid loss, circulating volume and electrolyte imbalance, insertion of nasogastric tube and urinary catheter improved surgical technique, broad spectrum antimicrobial therapy, analgesia and intensive care support has improved the outcome of such cases. Despite of modern treatment, complications are very common in cases of perforated gastrointestinal tract, even at centers with best facilities, because the outcome also depends on certain factors like degree and duration of peritoneal contamination, age and fitness of the patient and the nature of underlying cause.

In this study, an attempt is made to find out various 
preoperative and intra operative factors that may responsible for adverse outcome and to identify the best management that could decrease the complication rate with special reference to CLAVIEN-DINDO classification

\section{CLAVINE DINDO CLASSIFICATION}

The Clavien-Dindo system allows us to

1) Evaluate the quality of procedures and outcomes from a particular procedure

2) Compare different approaches or procedures as well as helps in comparison between surgeons, and health institutions

3) Analyze and records learning curves of surgical techniques.

4) Use it as the basis of improve quality of care and procedures

5) To standardize and measure surgical errors.

6) To accurately explain and compare different procedures to their patients in terms of risks and complications

Thereby improving management and prevention. The therapy used to correct a specific complication is the basis of this classification in order to rank a complication in an objective and reproducible manner. It consists of 7 grades (I, II, IIIa, IIIb, IVa, IVb and V).

\section{METHODS AND DEFINITIONS OF COMPLICATIONS Types of Outcome}

The outcomes have been classified into complications, and sequelae. Complications have been defined as any deviation from the normal postoperative course. This definition also takes into account asymptomatic complications such as ancemia, arrthymia.

Sequaele is a chronic condition that is a complication which follows a more acute condition.

\section{Classification of Surgical Complications}

The current modified classification is presented in Table I below with clinical examples. The management used to correct a specific complication remains the mainstay to categorized a complication. The classification had 7 grades, including 2 subgroups for grades 3 and 4, grades (I, II, IIIa, IIIb, IVa, IVb and V)

Table 1: Classification of surgical complications as per the classification proposed by Clavien-Dindo et al.

\begin{tabular}{|l|l|}
\hline Grade & Definition \\
\hline Grade I & $\begin{array}{l}\text { Any deviation from the normal postoperative } \\
\text { Course without the need for pharmacological } \\
\text { treatment or surgical, endoscopic and } \\
\text { radiological interventions. } \\
\text { Acceptable therapeutic regimens are: drugs as } \\
\text { antiemetics, antipyretics, analgetics, diuretics } \\
\text { and electrolytes and physiotherapy. This grade } \\
\text { also includes wound infections opened at the } \\
\text { bedside. }\end{array}$ \\
\hline Grade II & $\begin{array}{l}\text { Requiring pharmacological treatment with } \\
\text { drugs other than such allowed for grade I } \\
\text { complications. } \\
\text { Blood transfusions and total parenteral nutrition } \\
\text { are also included. }\end{array}$ \\
\hline Grade III & $\begin{array}{l}\text { Requiring surgical, endoscopic or radiological } \\
\text { intervention }\end{array}$ \\
\hline Grade III-a & Intervention not under general anesthesia \\
\hline Grade III-b & Intervention under general anesthesia \\
\hline Grade IV & $\begin{array}{l}\text { Life-threatening complication (including CNS } \\
\text { complications) }{ }^{*} \text { requiring IC/ICU-management }\end{array}$ \\
\hline Grade IV-a & single organ dysfunction (including dialysis) \\
\hline Grade IV-b & multi organ dysfunction \\
\hline Grade V & Death of a patient \\
\hline
\end{tabular}

\begin{tabular}{|l|l|}
\hline Suffix 'd' & If the patient suffers from a complication at the
\end{tabular} time of discharge, the suffix "d" (for 'disability') is added to the respective grade of complication. This label indicates the need for a follow-up to fully evaluate the complication.

\# brain hemorrhage, ischemic stroke, subarrachnoidal bleeding, but excluding transient ischemic attacks (TIA); IC: Intermediate care; ICU: Intensive care unit

\section{AIM \& OBJECTIVES}

\section{AIM}

Clinical study of Clavien-Dindo classification to assess the grades of complication and factors responsible in cases of gastrointestinal perforations in a tertiary care centre.

\section{OBJECTIVES OF THE STUDY}

1. To assess the factors responsible for deviation in outcome in gastrointestinal perforation.

2. To identify the diagnostic accuracy of used investigations tool to detect different organ perforation.

3. To assess the relation between pre-operative factors responsible for deviation in post-operative course \& its relation with grades of complications observed by Clavien-Dindo classification.

4. To study the postoperative outcome during hospital stay and at discharge

\section{MATERIALS AND METHODS}

We did an observational study of all perforation peritonitis patients admitted in Department of Surgery, Sri Aurobindo Medical College and Post Graduate Institute, Indore, M.P. between November 2017 to Mary 2019(1 and 1/2 Year) on the basis of Clavien-Dindo classification.

1) All the patients of perforation peritonitis who were admitted \& managed in Department of Surgery at Sri Aurobindo Medical College and Post Graduate Institute between November 2017 to May 2019(1 and 1/2 Year) were studied with respect to clinical features, time of presentation, comorbid conditions, investigations, intervention done, operative findings and postoperative course and all the data was entered in preformed proforma.

\section{INCLUSION CRITERIA : -}

1. Patients who are willing for study.

2. All the patients both male and female in the age group more than 10 years with peritonitis caused by perforation of the gastrointestinal tracts were included in this study.

\section{EXCLUSION CRITERIA : -}

1. Patients who are not willing for study

2. All the patients with primary peritonitis, Anastomosis leakage causing postoperative peritonitis and corrosive.

3. Children below than 10 years.

\section{DATA COLLECTION AND METHODS: -}

Selection of cases: An informed written consent was taken from all the patients / relatives in groups after the approval of institutional ethic committee.

Source of data: Patients admitted to Sri Aurobindo medical college and post graduate institute, Indore (M.P.)

\section{SAMPLE: -}

Total 60 patients of perforation peritonitis undergoing laparotomy were included according to the inclusion and exclusion criteria decided early in this study during the period of one and half year.

Data collection from patients by their clinical history, examination, with appropriate investigations. The cases were evaluated by history, clinical features and special tests if any required 


\section{METHOD OF DATA COLLECTION:}

From cases attending our institute in which diagnosis of peritonitis is established by operative findings or surgical interventions during management. Therefore, nonrandomized sampling technique was used.

\section{Pre designed semi structure questions were used}

The study was approved by the institutional ethics committee and in line with the declaration of Helsinki and followedthe guidelines laid out by the Indian council of medical research (ICMR).Written informed consent was taken from the patients participating in the study.

\section{PROCEDURE PLAN: -}

Patients presenting with gastrointestinal perforation coming in SAMC \& PG Institute \& admitted in Department of Surgery following details was recorded.Name, age, occupation, residence was recorded as per proforma case sheet. The presenting complaints and details were recorded in chronological orders.Patient's brief history was inquired and detail examination was done. General and systemic examination was done.These details were taken at the time of admission of patient to the hospital.Pre anesthetic check-up was before the surgery.Informed and written consent was taken from the patient and his/her relatives.Patient was kept nil by mouth 8 hours before the procedure according to NPO guidelines
Following investigations were done before the procedure According to the site of perforation various surgical procedure were performed.Data was during preoperative, intraoperative and postoperative period.

\section{INVESTIGATIONS: -}

- Routine investigations:OT-Profile, serum electrolyte ESR, ECG , PT ,INR

- Specific investigations: Chest $\mathrm{X}$ ray PA view,CECT abdomen, Liver function tests ,Post-Operative Histopathology Report,USG whole abdomen,X-RAY abdomen erect

\section{STATISTICAL ANALYSIS PLAN: -}

- Percentage was used to represent the data.

- Data was analyzed using descriptive statistics and chisquare test. Suitable statistics software utilized for analysis and presented in the form of tables, figures, graphs and diagrams whenever necessary.

- Pvalve < 0.05 was considered as statistically significant.

- The outcome was measured as better outcome (Grades I, II, and No complications) and worse outcome (Grades III, IV, V and VI)

- According to clavien dindo classification, complications are represented by grade I-IV

- Microsoft excel was used to prepare the master charts.

\section{OBSERVATION AND RESULTS}

Table 2: Age, Comorbid Condition and Outcome

\begin{tabular}{|c|c|c|c|c|c|c|c|c|c|}
\hline \multirow{3}{*}{$\begin{array}{l}\text { Āge } \\
(\mathrm{N}) \%\end{array}$} & \multicolumn{2}{|l|}{ Sex } & \multirow{3}{*}{\begin{tabular}{|l|} 
Total \\
No. $\mathrm{N}=60(\%)$ \\
\end{tabular}} & \multirow{2}{*}{\multicolumn{2}{|c|}{ Comorbid Condition }} & \multirow{2}{*}{\multicolumn{2}{|c|}{ Outcome }} & \multirow[b]{3}{*}{ Chi Square Value } & \multirow[b]{3}{*}{ P Value } \\
\hline & \multirow{2}{*}{$\begin{array}{l}\text { Male } \\
\mathrm{N}=41\end{array}$} & \multirow{2}{*}{$\begin{array}{l}\text { Female } \\
\mathrm{N}=19\end{array}$} & & & & & & & \\
\hline & & & & Present & Absent & Discharge & Expired & & \\
\hline$<20$ Years & $02(66.6 \%)$ & $01(33.3 \%)$ & $03(5 \%)$ & - & $03(100 \%)$ & $03100 \%)$ & 00 & 6.30 & 0.043 \\
\hline 20-39 Years & \begin{tabular}{|l}
19 \\
$(55.8 \%)$
\end{tabular} & \begin{tabular}{|l|}
15 \\
$(44.11 \%)$
\end{tabular} & $\begin{array}{l}34 \\
(56 \%)\end{array}$ & $\begin{array}{l}05 \\
(14.70 \%)\end{array}$ & $29(85.29 \%)$ & $\begin{array}{l}25 \\
(73.52 \%)\end{array}$ & $\begin{array}{l}09 \\
(26.47 \%)\end{array}$ & 24.8 & $<0.001$ \\
\hline 40-59 Years & $1386.6 \%$ & $0213.33 \%$ & $15(25 \%)$ & \begin{tabular}{|l|}
08 \\
$(53.33 \%)$
\end{tabular} & \begin{tabular}{|l|}
07 \\
(46.66\%)
\end{tabular} & \begin{tabular}{|l|}
10 \\
$(66.66 \%)$
\end{tabular} & \begin{tabular}{|l|}
05 \\
(33.33\%)
\end{tabular} & 3.94 & 0.139 \\
\hline 60 or More Years & $07(87.5 \%)$ & $01(12.5 \%)$ & $08(13.33 \%)$ & $02(25 \%)$ & $06(75 \%)$ & $08(100 \%)$ & 00 & 12.5 & 0.002 \\
\hline
\end{tabular}

The above table 02 shows that the distribution of patients according to age and gender. The age group 20 or less has least number of patients $3(5 \%)$ out of which $2(66.66 \%)$ were male and $01(33 \%)$ was female. No patients had comorbidity $3(100 \%)$ and all the $3(100 \%)$ patients were discharged, the age group 20-39 years was the largest group comprising of 34 (56\%) patients out of which $19(55.8 \%)$ were male and 15 $(44.11 \%)$ were female, comorbid conditions were present in $05(14.70 \%)$ and absent in $29(85.29 \%)$ people $(85.29 \%)$. $25(73.52 \%)$ patients were discharged in this group and 9(26.47\%) patients expired,.

Table 3: Time of Presentation, Complication, Outcome

\begin{tabular}{|c|c|c|c|c|c|c|}
\hline \multirow{2}{*}{$\begin{array}{c}\text { Time of } \\
\text { presentation }\end{array}$} & \multicolumn{2}{|c|}{ Complication } & \multicolumn{2}{|c|}{ Outcome } & \multirow{2}{*}{$\begin{array}{c}\text { Chi } \\
\text { square } \\
\text { value }\end{array}$} & \multirow{2}{*}{$\begin{array}{c}\mathrm{P} \\
\text { value }\end{array}$} \\
\hline & Present & Absent & Discharge & Expired & & \\
\hline $\begin{array}{c}1 \text { day or less } \\
(04) \\
(6.66 \%)\end{array}$ & $\begin{array}{c}1 \\
(25 \%)\end{array}$ & $\begin{array}{c}3 \\
(75 \%)\end{array}$ & $\begin{array}{c}04 \\
(100 \%)\end{array}$ & & 4.8 & 0.028 \\
\hline
\end{tabular}

\begin{tabular}{|c|c|c|c|c|c|c|}
\hline $\begin{array}{c}2-3 \text { days (36) } \\
(60 \%)\end{array}$ & $\begin{array}{c}23 \\
(63 . \\
88 \%)\end{array}$ & $\begin{array}{c}13 \\
(36 . \\
11 \%)\end{array}$ & $\begin{array}{c}35 \\
(97.22 \%)\end{array}$ & $\begin{array}{c}01 \\
(2.77 \%)\end{array}$ & 12.8 & $<0.001$ \\
\hline $\begin{array}{c}>3 \text { days }(20) \\
(33.33 \%)\end{array}$ & $\begin{array}{c}20 \\
(100 \%)\end{array}$ & - & $\begin{array}{c}07 \\
(35 \%)\end{array}$ & $\begin{array}{c}13 \\
(65 \%)\end{array}$ & 19.33 & $<0.001$ \\
\hline
\end{tabular}

Above Table-3 shows that Patients presenting within 1 day or less from the onset of symptoms were $4(6.66 \%)$ out of which complications occurred in $1(25 \%)$ patient rest $3(75 \%)$ had normal recovery. All the 4 patients in this group got discharged. Chi Square Value was 4.8 and P Value was 0.028 which is significant.In our study Majority of patients presented within 2-3 days from the onset of symptoms $36(60 \%)$ out of which complications occured in $23(63.88 \%)$ patients and recovery without complication in 13(36.11) patients. In this group $35(97.22 \%)$ patients got discharged and $1(2.77 \%)$ patient expired. Chi Square Value was 12.8 and $P$ Value was $<0.001$ which is significant.

Table 4: Time Of Presentation, Size Of Perforation, Haemodynamic

\begin{tabular}{|c|c|c|c|c|c|c|c|c|}
\hline \multirow{2}{*}{$\begin{array}{c}\text { Time } \\
\text { of Presentation }\end{array}$} & \multicolumn{2}{|c|}{ Size of Perforation } & \multicolumn{1}{|c|}{ Haemodynamic condition } & \multicolumn{2}{|c|}{ Outcome } & Chi square test & P value \\
\cline { 2 - 8 } & $1^{*} l \mathrm{~cm}$ & $>1^{*} l \mathrm{~cm}$ & Stable & Unstable & Discharge & Expired & & 11.1 \\
\hline $\begin{array}{c}\text { l day or less (04) } \\
(6.66 \%)\end{array}$ & $4(100 \%)$ & - & $04(100 \%$ & - & $04(100 \%)$ & - & 0.011 \\
\hline $\begin{array}{c}2-3 \text { days (36) } \\
(60 \%)\end{array}$ & $26(72.22 \%)$ & $10(27.77 \%)$ & $27(75 \%)$ & $09(25 \%)$ & $35(97.22 \%)$ & $01(2.77 \%)$ & 12.4 & 0.006 \\
\hline $\begin{array}{c}>3 \text { days (20) } \\
(33.33 \%)\end{array}$ & $08(40 \%)$ & $12(60 \%)$ & $03(15 \%)$ & $17(85 \%)$ & $07(35 \%)$ & $13(65 \%)$ & 32.3 & $<0.001$ \\
\hline
\end{tabular}


Above Table No. 4 shows that Patients presenting within 1 day or less from the onset of symptoms were 4 (6.66\%) out of which all $4(100 \%)$ patients had size of perforation ${ }^{*} 1 \mathrm{~cm}$ or less and in this group all $04(100 \%)$ patients were haemodynamically stable. All the 4 patients in this group got discharged. Chi-Square Value was 11.1 and P Value was 0.011 which is significant.Majority of patients presented within 2-3 days from the onset of symptoms in this group haemodynamically stable patient were $27(75 \%)$ and haemodynamically unstable were 09 (25\%) patients. Out of total patients in group 35(97.22\%) patients got discharged and 1 (2.77\%) patient expired. Chi Square Value was 12.4 and $P$ Value was 0.006 which is significant. Patients who presented after 3 days from onset of symptoms $20(33.33 \%)$,. In this group haemodynamically stable patient were $03(15 \%)$ and haemodynamically unstable were 17 (85\%) patients. out of total patients in this group 7 patient got discharged $7(35 \%)$ and 13 patients expired. Chi Square Value was 19.33 and P Value was $<0.001$ which is significant

Table 5: Comorbid Condition, Time Of Presentation, Haemodynamic Condition and Outcome

\begin{tabular}{|c|c|c|c|c|c|c|c|c|c|}
\hline \multirow{2}{*}{$\begin{array}{c}\text { Comorbid } \\
\text { Condition }\end{array}$} & \multicolumn{2}{|c|}{ Time of Presentation } & Haemodynamic Condition & \multicolumn{2}{c|}{ Outcome } & Chi square test & P value \\
\cline { 2 - 10 } & $\begin{array}{c}\text { 1 Day } \\
\text { or Less }\end{array}$ & $\begin{array}{c}2-3 \\
\text { Days }\end{array}$ & $\begin{array}{c}>\mathbf{3} \\
\text { Days }\end{array}$ & Stable & Un stable & Discharge & Expired & & \\
\hline Present (16) & - & 4 & 12 & 04 & 12 & 07 & 09 & 1.75 & 0.418 \\
$26.60 \%$ & & $25 \%$ & $75 \%$ & $25 \%$ & $75 \%$ & $43.75 \%$ & $56.25 \%$ & & \\
\hline Absent (44) 73.33\% & $49.09 \%$ & $3272.7 \%$ & $818.18 \%$ & $3068.18 \%$ & $1431.81 \%$ & $3988.63 \%$ & $0511.36 \%$ & 5.54 & 0.020 \\
\hline
\end{tabular}

Above Table-5 shows that in those $16(26.6 \%)$ patients whom comorbid condition present $4(25 \%)$ patient presented with in 2-3 days, $12(75 \%)$ presented after 3 days and none of them presented within 1 days of onset of symptom, the haemodynamically stable were 04 (25\%) patients and unstable were $12(75 \%)$ patients. In this group $07(43.75 \%)$ patients got discharged and $9(56.25 \%)$ patient expired. Chi Square Value was 1.75 and P Value was 0.418 which is not significant [however this table shows clearly increase in haemodynamically unstability and mortality in presence of comorbid condition].
Comorbidities were absent in $44(73.33 \%)$ patient in those $32(72.7 \%)$ presented with in 2-3 days, 08 (18.18\%) presented after 3 days and $4(9.09 \%)$ patient presented within 1 days of onset of symptom, of these the haemodynamically stable were $30(68.18 \%)$ patients and unstable were $14(31.81 \%)$ patients. In this group $39(88.63 \%)$ patients got discharged and 5 (11.36\%) patient expired. Chi Square Value was 5.54 and P Value was 0.020 which is significant. [for comorbid condition, haemody namically condition \& outcome]

Table 6: Size of Perforation, Comorbid Condition and Complication

\begin{tabular}{|c|c|c|c|c|c|c|}
\hline \multirow{2}{*}{ Size of perforation } & \multicolumn{2}{|c|}{ Comorbid condition } & \multicolumn{2}{|c|}{ Complication } & Chi square Test & P value \\
\cline { 2 - 7 } & Present & Absent & Present & Absent & & \\
\hline $1^{*} l \mathrm{~cm}$ or less (31) (51.66\%) & $0619.35 \%$ & $2588.64 \%$ & $1651.61 \%$ & $1548.38 \%$ & 7.05 & 0.008 \\
\hline$>1^{*} 1 \mathrm{~cm}(29)(48.33 \%)$ & $1032.25 \%$ & $1965.51 \%$ & $2896.55 \%$ & $013.44 \%$ & 24.7 & $<0.001$ \\
\hline
\end{tabular}

Above Table No. 6 shows that 31 (51.66\%) patient has perforation less or upto $1 \mathrm{~cm}$ size in this group in 06(19.35\%) comorbid condition were present and absent in 25(88.64\%), complication occurred in $16(51.61 \%)$ patients and no complication observed in 15(48.38\%) patients .Chi Square Value was 7.05 and P Value was 0.008 which is significant.

In $29(48.33 \%)$ patient size of perforation was more than $1 \mathrm{~cm}$ out of which in 10(32.25\%) patients comorbid condition were present, absent in $19(65.51 \%)$ patient, complication observed in $28(96.55 \%)$ patient and in only 01 (3.44\%)patient there was no complication.Chi Square Value was 24.7 and P Value was $<0.001$ which is significant.

Morbidity and complication were higher for cases of $>/=1 \mathrm{~cm}$ of perforation as compared to those with perforation less than $1 \mathrm{~cm}$. Thus, size of perforation affects mortality and morbidity in perforation peritonitis

Table 7: Number of Perforation, Haemodynamic Condition, Complication and Outcome

\begin{tabular}{|c|c|c|c|c|c|c|c|c|}
\hline \multirow{2}{*}{$\begin{array}{c}\text { Number } \\
\text { of Perforation }\end{array}$} & \multicolumn{2}{|c|}{ Haemodynamic Condition } & \multicolumn{2}{|c|}{ Complication } & \multicolumn{2}{|c|}{ Outcome } & \multirow[t]{2}{*}{ Chi square test } & \multirow[t]{2}{*}{ P value } \\
\hline & Stable & Un stable & Present & Äbsent & Discharge & Expired & & \\
\hline $\begin{array}{c}\text { Single Perforation (50) } \\
83.33 \%\end{array}$ & $3366 \%$ & $1734 \%$ & $370 \%$ & $1530 \%$ & $4284 \%$ & $0816 \%$ & 4.57 & 0.102 \\
\hline $\begin{array}{c}\text { Multiple Perforation (10) } \\
(16.66 \%)\end{array}$ & $0110 \%$ & $0990 \%$ & $0990 \%$ & $\begin{array}{c}01 \\
10 \%\end{array}$ & $\begin{array}{c}04 \\
40 \%\end{array}$ & $\begin{array}{c}06 \\
60 \%\end{array}$ & 13.1 & 0.001 \\
\hline
\end{tabular}

Above Table 7 study reveals that $50(83.33 \%)$ patients had single perforation out of which $33(66 \%)$ patients were haemodynamically stable and $17(34 \%)$ patients were unstable, complication occurred in $35(70 \%)$ patients and no complication found in $15(30 \%)$.In this group $42(84 \%)$ patients got discharged and 8(16\%) patient expired. Chi Square Value was 4.57 and $P$ Value was $<0.102$ which is not significant.
In $10(16.66 \%)$ patients multiple perforations were found out of which only 01 (10\%) patient is haemodynamically stable and $09(90 \%)$ patients were unstable, complication occurred in 09(90\%) patients and no complication were only in 01 (10\%) patients. In this group $04(40 \%)$ patients got discharged and 6(60\%) patient expired. Chi Square Value was 13.1 and $P$ Value was 0.001 which is significant

Table 8: Intra-peritoneal Collection, Complication, Haemodynamic Condition, Duration of Hospital Stay and Outcome

\begin{tabular}{|c|c|c|c|c|c|c|c|c|c|c|}
\hline \multirow{2}{*}{$\begin{array}{c}\text { Intra } \\
\text { Peritoneal } \\
\text { Collection }\end{array}$} & \multicolumn{2}{|c|}{ Complication } & \multicolumn{2}{|c|}{$\begin{array}{c}\text { Haemodynamic } \\
\text { Condition }\end{array}$} & \multicolumn{2}{|c|}{ Duration of Hospital Stay } & \multicolumn{2}{|c|}{ Outcome } & \multirow[b]{2}{*}{ Chi square test } & \multirow[b]{2}{*}{ P value } \\
\hline & Present & Absent & Stable & Unstable & Upto 14 Days & >14 Days & Discharge & Expired & & \\
\hline $\begin{array}{l}\text { UPTO } 500 \mathrm{ml} \\
(36)(60 \%)\end{array}$ & \begin{tabular}{|c|}
20 \\
$55.55 \%$ \\
\end{tabular} & $\begin{array}{c}16 \\
44.44 \% \\
\end{array}$ & $\begin{array}{c}28 \\
77.77 \% \\
\end{array}$ & $\begin{array}{c}8 \\
22.22 \% \\
\end{array}$ & $\begin{array}{c}17 \\
47.22 \% \\
\end{array}$ & $\begin{array}{c}19 \\
52.77 \% \\
\end{array}$ & $\begin{array}{c}35 \\
97.22 \% \\
\end{array}$ & $\begin{array}{c}01 \\
2.77 \% \\
\end{array}$ & 25.9 & $<0.001$ \\
\hline $\begin{array}{c}>500 \mathrm{ml}(24) \\
(40 \%)\end{array}$ & $\begin{array}{c}24 \\
100 \%\end{array}$ & - & $\begin{array}{c}06 \\
25 \%\end{array}$ & $\begin{array}{c}18 \\
75 \%\end{array}$ & $\begin{array}{c}10 \\
41.66 \%\end{array}$ & $\begin{array}{c}14 \\
58.33 \%\end{array}$ & $\begin{array}{c}11 \\
45.83 \%\end{array}$ & $\begin{array}{c}13 \\
54.16 \%\end{array}$ & 42.8 & $<0.001$ \\
\hline
\end{tabular}


Above Table No. 8 shows that In our study intraperitoneal collection upto $500 \mathrm{ml}$ is found in $36(60 \%)$ patient out of the group complication developed in $20(55.55 \%)$ patient and no complication seen in $16(44.44 \%)$ patients, haemodynamic stability seen in $28(77.77 \%)$ patients \& unstability present in $8(22.22 \%)$ patients ,duration of hospital stay upto 14 days in $17(47.22 \%)$ and more than 14 days in $19(52.77 \%)$ patients. In this group $35(97.22 \%)$ patients got discharged and $1(2.77 \%)$ patient expired. Chi Square Value was 25.9 and P Value was $<0.001$ which is significant.
In second group intraperitoneal collection more than 500 $\mathrm{ml}$ is found in $24(40 \%)$ patient out of the group complication developed in all 24(100\%)patient, haemodynamic stability seen in $06(25 \%)$ patients \& unstability present in $18(75 \%)$ patients, duration of hospital stay upto 14 days in $10(41.66 \%)$ and more than 14 days in $14(58.33 \%)$ patients. In this group $11(45.83 \%)$ patients got discharged and $13(54.16 \%)$ patient expired. Chi Square Value was 42.8 and $P$ Value was $<0.001$ which is significant.

Table 9: Various Surgical Procedures According to Perforation Site and Outcome in Relation to Clavien- Dindo Classification

\begin{tabular}{|c|c|c|c|c|c|c|}
\hline $\begin{array}{c}\text { Site of } \\
\text { Perforation }\end{array}$ & \begin{tabular}{|c|} 
No, of \\
Patient
\end{tabular} & $(\%)$ & Surgical Procedure & $\begin{array}{c}\text { Better Outcome (clavien- } \\
\text { dindo classification No } \\
\text { Complication, Grade-I, } \\
\text { Grade-II,) } \\
\text { N (\%) } \\
\end{array}$ & \begin{tabular}{|c|} 
Worse Outcome \\
(Clavien-Dindo \\
Grade III, IV and \\
V) \\
N (\%) \\
\end{tabular} & \\
\hline GASTRIC* $^{*}$ & 30 & $49.18 \%$ & $\begin{array}{l}\text { Grahm's Patch Repair (11)(36\%) } \\
\text { Modified Grahm's Patch Repair } \\
\text { (19) (64\%) }\end{array}$ & $\begin{array}{l}05(45 \%) \\
08(42 \%)\end{array}$ & $\begin{array}{l}06(55 \%) \\
11(58 \%)\end{array}$ & \begin{tabular}{|cc|}
\multicolumn{2}{c|}{ Chi square test- } \\
$0.031 \quad$ Df- 01 \\
P value- 0.858
\end{tabular} \\
\hline ILEUM* & 23 & $37.7 \%$ & $\begin{array}{l}\text { Primary Repair (15) (65.21\%) } \\
\text { Ileostomy With/Without } \\
\text { Primary Repair (03) (13.04\%) } \\
\text { Resection and Anastomosis } \\
\text { (05) (21.74\%) }\end{array}$ & $\begin{array}{l}06(40 \%) \\
02(40 \%)\end{array}$ & $\begin{array}{l}09(60 \%) \\
03(100 \%) \\
03(60 \%)\end{array}$ & \begin{tabular}{|l|} 
Chi square test- \\
$1.84, \quad$ Df- 02, \\
P value- 0.399
\end{tabular} \\
\hline JEJUNUM & 03 & $4.91 \%$ & $\begin{array}{l}\text { Primary Repair (02) (66.66\%) } \\
\text { Resection and Anastomosis } \\
\text { (01) (33.33\%) }\end{array}$ & $01(50 \%)$ & $\begin{array}{l}01(50 \%) \\
01(100 \%)\end{array}$ & \begin{tabular}{|c|} 
Chi square test- \\
0.750, df- 1 \\
P value- 0.386
\end{tabular} \\
\hline COLON & 03 & $4.91 \%$ & \begin{tabular}{|c|} 
Colostomy (01) (33.33\%) \\
colostomy with Primary Repair (02) \\
$(66.66 \%)$
\end{tabular} & $01(100 \%)$ & $02(100 \%)$ & \begin{tabular}{|c|} 
Chi square test- \\
3.00, df- 1 \\
P value- 0.083
\end{tabular} \\
\hline APPENDIX & 01 & $1.63 \%$ & Appendectomy (01) (100\%) & & $01(100 \%)$ & NA \\
\hline RECTUM & 01 & $1.63 \%$ & $\begin{array}{c}\text { Hartman's Procedure } \\
(100 \%)\end{array}$ & & $01(100 \%)$ & NA \\
\hline
\end{tabular}

SURGICAL PROCEDURES ACCORDING TO PERFORATION SITE AND OUTCOME IN RELATION TO CLAVIEN-DINDO CLASSIFICATION

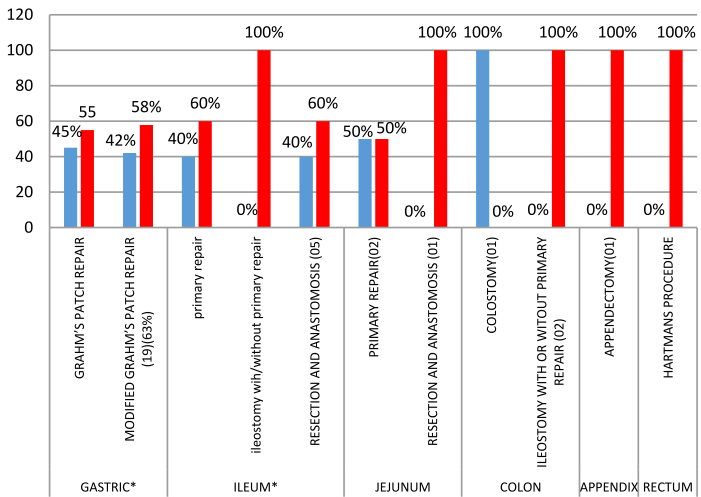

SITE OF PERFORATION

- BETTER OUTCOME — WORSE OUTCOME

Graph 1: Bar chart showing Various Surgical Procedures According to Perforation Site and Outcome in Relation to Clavien-Dindo Classification

Above Table No.9 \& Graph No. 1 shows that Most of gastric perforation $30(49.18 \%)$ was managed by grahm's patch repairll (36\%), $5(45 \%)$ patient had better outcome and 6 $(55 \%)$ patient had worse outcome. modified grahm's patch repair in 19 (64\%), 8 (42\%) patient had better outcome and 11
(58\%) patient had worse outcome.

Next major group was ileal perforation 23(37.7\%) was managed by primary repair $15(65.21 \%), 6(40 \%)$ patient had better outcome and $9(60 \%)$ patient had worse outcome. Ileostomy with or without primary repair done in 03 (\%), all $3(100 \%)$ had worse outcome and resection and anastomosis done in $05(21.74 \%)$ patients, $2(40 \%)$ patient had better outcome and $3(60 \%)$ patients had worse outcome.

Next was jejunum perforation $3(4.91 \%)$ was managed by primary repair $02(66.66 \%)$ patients, $01(50 \%)$ patient had better outcome, l (50\%) patient had worse outcome and resection and anastomosis done in $01(33.33 \%)$ patients $1(100 \%)$ patients had worse outcome Colon perforation seen in $3(4.91 \%)$ patients managed by colostomy in 1 (33.33\%) had better outcome whereas $2(66.66 \%)$ patient with primary repair $2(100 \%)$ patients both had worse outcome Appendix and rectum perforation seen in one (1.63\%) patient both of them had worse outcome

Pvalve is significant for gastric and ileal perforation Most common procedure performed was exploratory laparotomy with modified grahm's omental patch repair in 19 (31 \%) patients followed by primary repair in $17(27.86 \%)$ patient for ileal and jejunal perforation, grahm's patch repair done in $11(18.03 \%)$ patients, resection and anastomosis in 06 $(9.83 \%)$, ileostomy performed in $5(8.19 \%)$ patient , colostomy , appendectomy and Hartsmans procedure in 1 patient $(1.63 \%)$ respectively. 
Table 10: Clavien-Dindo classification system for surgical complication and management of complication

\begin{tabular}{|l|l|l|}
\hline COMPLICATION & MANAGEMENT & $\begin{array}{l}\text { CLAVIEN-DINDO'S CLASSIFICATION } \\
\text { (Grades I, II, III, IV, V) }\end{array}$ \\
\hline NO COMPLICATION & NO ADDITIONAL MANGEMENT & NO COMPLICATION (14) (23.33\%) \\
\hline $\begin{array}{l}\text { WOUND INFECTION/WOUND } \\
\text { LEHISCENCE }\end{array}$ & OPENED AT BED SIDE \& DRESSING & GRADE I (4) (6.66\%) \\
\hline LOSS OF BLOOD AND CATABOLISM & $\begin{array}{l}\text { BLOOD TRANSFUSION \& TOTAL } \\
\text { PARENTRAL NUTRITION }\end{array}$ & GRADE II (5) (8.33\%) \\
\hline $\begin{array}{l}\text { (a) PLEURAL EFFUSION } \\
\text { (b) BURST ABDOMEN/ LEAK }\end{array}$ & $\begin{array}{l}\text { PLEURAL TAPPING } \\
\text { SECONDRY CLOSURE/ } \\
\text { RE-EXPLORATION }\end{array}$ & $\begin{array}{l}\text { GRADE III- } \alpha \text { (3) (25\%) (12) (20\%) } \\
\text { GRADE III-b (9) (75\%) }\end{array}$ \\
\hline $\begin{array}{l}\text { (a) SINGLE ORGAN FAILURE } \\
\text { (b) MODS/ SEPTICEMIA }\end{array}$ & $\begin{array}{l}\text { ICU CARE } \\
\text { ICU CARE/VENTILLATORY } \\
\text { SUPPORT/DIALYSIS }\end{array}$ & $\begin{array}{l}\text { GRADE IV- } \alpha \text { (11) (18.33\%) } \\
\text { GRADE IV-b }\end{array}$ \\
\hline DEATH (14) (23.33\%) & - & GRADE V (14) (23.33\%) \\
\hline
\end{tabular}

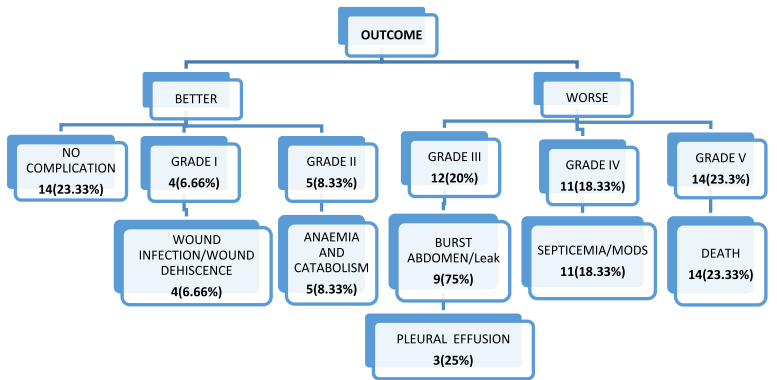

Graph 2: Flow chart Shows outcome and grading with postoperative complications of various perforations.

Above Table No. 10 and Graph no. 25 shows that the management of complications during hospital stay and from the study it was found that 14 out of $60(23.33 \%)$ patients are discharge with no complications, $4(6.66 \%)$ cases of wound infection/wound dehiscence were managed by sutures opened at bedside and regular sterile dressing done (grade I complication), 5 (8.33\%) patients had anaemia and catabolism were managed by blood transfusion and total parenteral nutrition (grade II complications), out of 12 (20\%), $3(25 \%)$ patients had pleural effusion managed by pleural tapping and 9 (75\%) had burst abdomen or leak managed by secondary closure /re-exploratory (grade III complications), $11(18.33 \%)$ patients of single organ failure, MODS/ septicaemia managed in ICU care/ventilator support/dialysis (grade IV complications), and 14 (23.33\%) patients expired ( grade $\mathrm{V}$ complication rates)

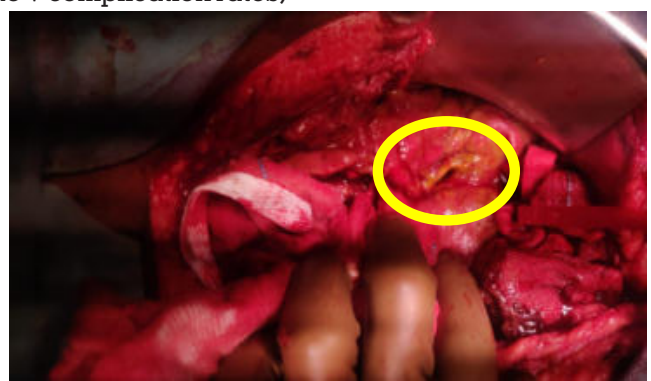

Figure 14: Showing prepyloric perforation

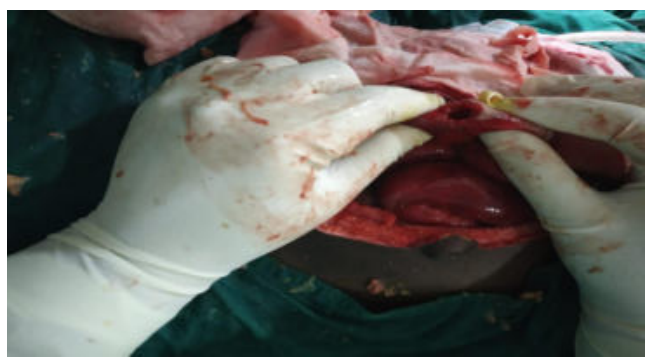

Figure 15: Showing ileal perforation

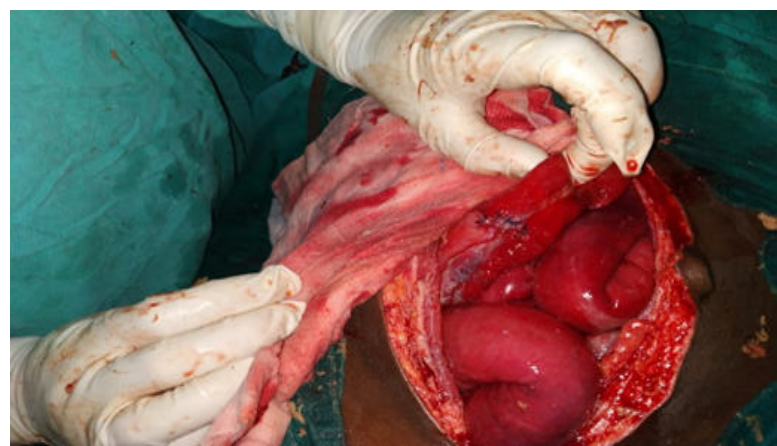

Figure 16: Showing primary repair of ileal perforation

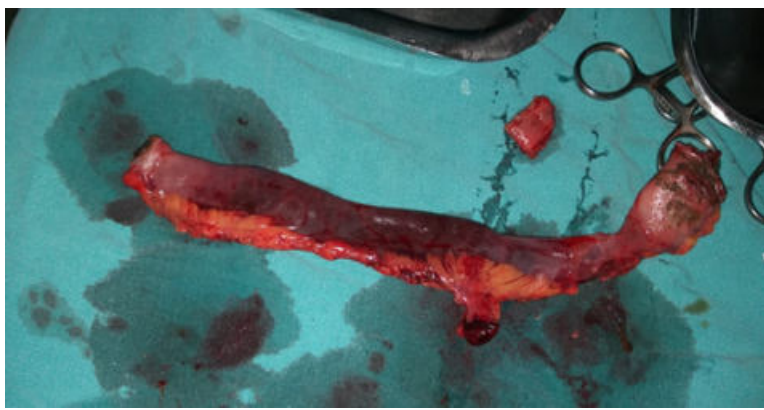

Figure 17: Showing Perforation with gangrenous bowel

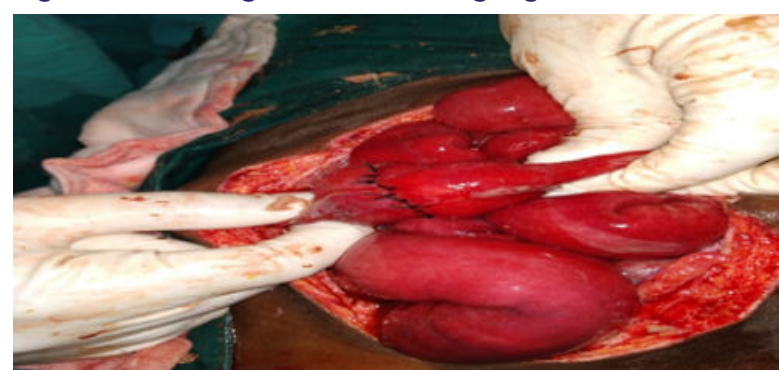

Figure 18: showing Resection and Anastomosis

\section{DISCUSSION}

The aim of the present study is to assess the complications and factors responsible for outcomes in cases of gastrointestinal perforations in a tertiary care centre and also, to find out various determinants for safe outcomes in gastrointestinal perforation in terms of decreased morbidity and mortality and applying Clavien-Dindo classification for postoperative complications for evaluating the outcome.

Despite of modern treatment, complications are very common in cases of perforated gastrointestinal tract, even at centers with best facilities, in this study, an attempt is made to find out various preoperative and intra operative factors that may responsible for adverse outcome and to identify the best management that could decrease the complication rate. In the 
present work entitled "Clinical Study of Clavien-Dindo Classification to Assess the Grades of Complication and Factors Responsible in Cases of Gastrointestinal Perforations in a Tertiary Care Centre c.

\section{1-AGE AND COMORBID CONDITION WISE DISTRIBUTION}

In our study the age group 20-39 years was the largest group comprising of 34 (56\%) patients out of which 19 (55.88\%) were male and $15(44 \%)$ were female, comorbid conditions were present in

\section{Similar studies: -}

1] Abdulhameed MME, et al. (2016) study shows that Maximum patients were in the age group of 20-39 year has 47 patient out of which $46(98 \%)$ patients recovered and $1(2 \%)$ patient expired, followed by age group 40-59 year has 28 patients out of which $20(71.5 \%)$ patients recovered and $8(28.5 \%)$ patient expired, Next age group of more than 60 year comprising of 21 patient out of which $15(71.5 \%)$ patients recovered and $6(28.5 \%)$ patient expired. The age group 20 year or less has 4 patient only out of which $4(100 \%)$ all patients are recovered and discharge.

2] Nabi I, et al. (2016) study shows that the patients varied from 19 to 60 years with most of the patients falling within the age range of $21-30$ years. Their mean age was 34.42 years. The majority of patients were male ( $77.6 \%$ male vs. $22.4 \%$ female).

3] Mewara B, et al. (2017) study shows that the mean age of presentation was 40.29 years, There are 89 males (89\%) and as compared to 11 females (11\%). Out of 100 patients, 7 patients $(7 \%)$ died in the post-operative period.

4] Singh A, et al. (2016) study shows that Most of the patients were $<40$ year of age (58\%). Majority of the patients were males (270 males and 80 females). The male-to-female ratio was 3.3:1.

5] Keshri A, et al. (2016) study shows thatout of 180 patient $142(82.22 \%)$ male and $32(17.78 \%)$ female. age group $<20$ year, 10 survied 1 died, Age goup 21-50, 101 survived 3 died, age group $>5061$ survied 4 died,

\section{II - TIME OF PRESENTATION}

In our study Majority of patients presented within 2-3 days from the onset of symptoms $36(60 \%)$ out of which complications occured in $23(63.88 \%)$ patients and recovery without complication in $13(36.11 \%)$ patients. In this group $35(97.22 \%)$ patients got discharged and $1(2.77 \%)$ patient expired, P Value was $<0.001$ which is significant. Next group was of patients who presented after 3 days from onset of symptoms $20(33.33 \%)$ all of them had complications $20(100 \%)$. However out of 20 patients. In this group 7 patient got discharged $7(35 \%)$ and $13(65 \%)$ patients expired P Value was $<0.001$ which is significant. Smallest group was of Patients presenting within 1 day or less from the onset of symptoms were 4 (6.66\%) out of which complications occurred in $1(25 \%)$ patient rest $3(75 \%)$ had normal recovery. All the 4 patients in this group got discharged P Value was 0.028 which is significant.

Similar studies: -

1] Abdulhameed MME, et al. (2016) - Out of 100 patients time of presentation 1 day or less is $29(29 \%)$ patients out of which $29(100 \%)$ is recovered and $0(0 \%)$ is expired, $2-3$ days $55(55 \%)$ patients out of which $49(89 \%)$ is recovered and $6(11 \%)$ is expired and more than 3 days $16(16 \%)$ patients out of which $6(37.5 \%)$ is recovered and $10(62.5 \%)$ is expired. Mean Time of presentation 2.27 days and standard deviation is 1.12 . Recovered 84 (84\%) patient and death 16 patient. Statistical test is ' $t$ ' test and $\mathrm{p}$ value are $<0.001$ implies mortality increases with delayed presentation.
2] Jobta R, et al.(2006) study shows that the time taken by the patient between onset of symptoms and presentation to the hospital was less than 24 hours in $235(47 \%)$ cases and more than 24 hours in $269(53 \%)$ cases.

3] Malik P, et al. (2014) study shows that less than 24 hours 532 (38\%) patient and more than 24 hours $868(62 \%)$ patient out of 1400 .

4] Mewara B, et al. (2017) study shows thatOut of 100 patients only 34 patients had presented within 24 hours of onset of symptoms and the $66 \%$ patients had presented after 24 hours of onset of symptoms. Out of 100 patients, 7 patients (7\%) died in the post-operative period. All of these 7 patients had presented late, after the 48 hours. The 14 patients had reported post-operative complications

\section{III - COMORBID CONDITION}

In our study comorbidities were absent in $44(73.33 \%)$ patient in those $32(72.7 \%)$ presented with in 2-3 days , 08 (18.18\%) presented after 3 days and $4(9.09 \%)$ patient presented within 1 days of onset of symptom, of these the haemodynamically stable were $30(68.18 \%)$ patients and unstable were 14 $(31.81 \%)$ patients. In this group $39(88.63 \%)$ patients got discharged and $5(11.36 \%)$ patient expired. and P Value was 0.020 which is significant. [for comorbid condition, haemodynamically condition \& outcome]

In those whom comorbid condition present 16 (26.6\%) patients in those 4 (25\%) patient presented with in 2-3 days, 12 (75\%) presented after 3 days and none of them presented within 1 days of onset of symptom, the haemodynamically stable were $04(25 \%)$ patients and unstable were $12(75 \%)$ patients. In this group 07(43.75\%) patients got discharged and 9(56.25\%) patient expired. Chi Square Value was 1.75 and P Value was 0.418 which is not significant [increase in haemodynamically unstability and mortality in presence of comorbid condition].

Similar study:-

1] Abdulhameed MME, et al. (2016) study shows that Comorbid condition present in 25 patient out of which 15 (60\%) patient is recoverd and $10(40 \%)$ is expired and absent in 75 out of which $69(92 \%)$ patient is recoverd and $6(8.1 \%)$. Statistical test is chi-square test and p-value 0.001 , which shows that comorbid conditions like diabetes, hypertension, COPD and renal failure increase mortality.

\section{IV-HAEMODYNAMIC CONDITION}

Majority of patients presented within 2-3 days from the onset of symptoms $36(60 \%)$ out of which in $26(72.22 \%)$ patients size of perforation was $1 \mathrm{~cm}$ or less and in $10(27.77 \%)$ patient it was more than $1^{*} 1 \mathrm{~cm}$.In this group haemodynamically stable patient were $27(75 \%)$ and haemodynamically unstable were $09(25 \%)$ patients. out of total patients in group 35(97.22\%) patients got discharged and 1 (2.77\%) patient expired. Chi Square Value was 12.4 and $P$ Value was 0.006 which is significant.

Next group of patients who presented after 3 days from onset of symptoms $20(33.33 \%)$, out of which in $08(40 \%)$ of them size of perforation was $1 \mathrm{~cm}$ or less\& in $12(60 \%)$ more than $l^{*} l \mathrm{~cm}$ size.In this group haemodynamically stable patient were 03(15\%) and haemodynamically unstable were 17 (85\%) patients. out of total patients In this group 7 patients got discharged 7(35\%) and 13 patient expired. Chi Square Value was 19.33 and $P$ Value was $<0.001$ which is significant.

\section{Similar studies:-}

1] Paryani JJ, etal. (2013) found that mortality rate was $80 \%$ for patients with blood pressure $<100 \mathrm{~mm} \mathrm{Hg}$

2] Kamble R S, et al. (2016) study shows that $7.69 \%$ of the cases with heart rate $<100 / \mathrm{min}$ died which was significantly 
less as compared to $25 \%$ of cases with heart rate $>/=100 / \mathrm{min}$, but difference was not statistically significant and $29.17 \%$ of the cases with heart rate $<100 /$ min had hospital stay $>10$ days which was less as compared to $61.11 \%$ of cases with $>/=100$ heart rate, and the difference was statistically significant.

This result shows that $35.71 \%$ of the cases with blood pressure $<90 \mathrm{mmHg}$ died which was significantly more as compared to $8.33 \%$ of cases with blood pressure $>/=90 \mathrm{mmHg}$, and the difference was statistically significant and $77.77 \%$ of the cases with blood pressure $<90 \mathrm{mmHg}$ had hospital stay $>10$ days which was more as compared to $33.33 \%$ with Blood Pressure $>/=90 \mathrm{mmHg}$, and the difference was statistically significant. This result indicates that, $8.57 \%$ of the cases with respiratory rate $<24 / \mathrm{min}$ died which was less as compared to $33.33 \%$ of the cases with respiratory rate $>/=24 / \mathrm{min}$, and the difference was statistically significant and $31.25 \%$ of the cases with respiratory rate $<24 /$ min had hospital stay $>10$ days which was les as compared to $80.00 \%$ of the cases with respiratory rate $>/=24 / \mathrm{min}$, and the difference was statistically significant.

\section{V - SIZE OF PERFORATION}

In our study 31 (51.66\%) patient has perforation less or upto 1 $\mathrm{cm}$ size in this group in 06(19.35\%) comorbid condition were present and absent in 25(88.64\%) complication occurred in 16 (51.61\%) patients and no complication observed in 15(48.38\%) patients. Chi Square Value was 7.05 and P Value was 0.008 which is significant.

In $29(48.33 \%)$ patient size of perforation was more than $1 \mathrm{~cm}$ out of which in $10(32.25 \%)$ patients comorbid condition were present, absent in 19 (65.51\%)patient, complication observed in $28(96.55 \%)$ patient and in only 01 (3.44\%)patient there was no complication. Chi Square Value was 24.7 and P Value was $<0.001$ which is significant

\section{Similar studies: -}

1] Abdulhameed MME et al. (2016) study shows that Size of perforation Up to $1 \mathrm{~cm}$ in 77 patient (77\%) out of which 71 (92\%) patient recovered and 6(8\%)patient expired and size of perforation is more than $1 \mathrm{~cm}$ in 23 patient out of which $15(65 \%)$ patient recovered and $8(35 \%)$ patient expired. Mean size of perforation is $1.29 \mathrm{~cm}$ and standard deviation is .518 . Statistical test is ' $t$ ' test and $p$ value are 0.001 implies size of perforation influence outcome.

2] Gupta S, et al. (2010) study shows thatSize of perforation is between $0-<0.5 \mathrm{~cm}$ in 293 patient, $0.5-<1 \mathrm{~cm}$ in 57 patient, 1$<2 \mathrm{~cm}$ in 35 patient and more than $2 \mathrm{~cm}$ in 15 patients.

\section{VI - NUMBER OF PERFORATION}

Our study reveals that $50(83.33 \%)$ patients had single perforation out of which $33(66 \%)$ patients were haemodynamically stable and $17(34 \%)$ patients were unstable, complication occurred in 35 (70\%) patients and no complication found in $15(30 \%)$. In this group $42(84 \%)$ patients got discharged and $8(16 \%)$ patient expired. Chi Square Value was 4.57 and $P$ Value was $<0.102$ which is not significant.

In 10 (16.66\%) patient's multiple perforations were found out of which only 01 (10\%) patient is haemodynamically stable and $09(90 \%)$ patients were unstable, complication occurred in $09(90 \%)$ patients and no complication were only in 01 (10\%) patients. In this group 04(40\%) patients got discharged and 6(60\%) patient expired. Chi Square Value was 13.1 and $P$ Value was 0.001 which is significant

Similar studies: -

1] Rao $R$, et al. (2016) study shows that there issingle perforation in $79 \%$ patient, two perforation in $4 \%$ patient and multiple perforation in $17 \%$ patient

2] Manikanta K S, et al. (2016) study shows that Single perforations were observed in $33(66 \%)$ patients, two perforations were found in $7(14 \%)$ patients, three perforations in $6(12 \%)$ patients, whereas four perforations were seen in $4(8 \%)$ patients.

\section{VII-INTRAPERITONEAL COLLECTION}

In our study intraperitoneal collection upto $500 \mathrm{ml}$ is found in $36(60 \%)$ patient out of the group complication developed in $20(55.55 \%)$ patient and no complication seen in $16(44.44 \%)$ patients, haemodynamic stability seen in $28(77.77 \%)$ patients \& unstability present in $8(22.22 \%)$ patients, duration of hospital stay upto 14 days in $17(47.22 \%)$ and more than 14 days in $19(52.77 \%)$ patients. In this group $35(97.22 \%)$ patients got discharged and $1(2.77 \%)$ patient expired. Chi Square Value was 25.9 and $P$ Value was $<0.001$ which is significant.

In second group intraperitoneal collection more than $500 \mathrm{ml}$ is found in $24(40 \%)$ patient out of the group complication developed in all $24(100 \%)$ patient, haemodynamic stability seen in 06(25\%) patients \& unstability present in $18(75 \%)$ patients, duration of hospital stay upto 14 days in $10(41.66 \%$ ) and more than 14 days in $14(58.33 \%)$ patients. In this group 11 $(45.83 \%)$ patients got discharged and $13(54.16 \%)$ patient expired. Chi Square Value was 42.8 and P Value was $<0.001$ which is significant.

\section{Similar studies: -}

Kamble R S, et al. (2016) Out of 50 patients 16 patients had $>/=1000 \mathrm{ml}$ of contamination out of which 5 died which was more than the patients died of having $<1000 \mathrm{ml}$ contamination. There result reveals that, $8.8 \%$ of cases with $<1000 \mathrm{ml}$ of contamination died which was significantly less as compared to $31.2 \%$ of cases with $>/=1000 \mathrm{ml}$, and the difference is statistically significant and $29.0 \%$ of the cases with $<1000 \mathrm{ml}$ contamination had $>10$ days hospital stay which was significantly less as compared to $81.8 \%$ of cases with $>/=1000 \mathrm{ml}$ and the difference is statistically significant.

\section{VIII-HOSPITAL STAY}

In our study Most of gastric perforation 29(49.18\%). Duration of hospital stay upto 14 days in $14(48.27 \%)$ patient and more than 14 days in 15(51.72\%) patient Followed by ileal perforation 22(36.66\%). Duration of hospital stay upto 14 days in $11(50 \%)$ patient and more than 14 days in $11(50 \%)$ patient Next was jejunum perforation 3(5\%)Duration of hospital stay upto 14 days in $1(33.33 \%)$ patient and more than 14 days in 02(66.66\%) patient, Colon perforation seen in $3(5 \%)$ Duration of hospital stay upto 14 days in $1(33.33 \%)$ patient and more than 14 days in 02(66.66\%) patient Appendix, rectum perforation and gastric and ileal perforation both seen in $1(1.63 \%)$ patient each of them had duration of hospital stay more than 14 days with complication present.

similar studies: -

1] Manikanta KS, et al. (2016) study shows that the length of hospital stay ranged from 6 days to 22 days, the average hospital stay being 13.28 days. The patients who underwent simple primary closure had an average stay of 12.7 days. Their counterparts who had the procedure of resection anastomosis had an average stay of 14.4 days

\section{IX-COMPLICATIONS}

In our study 14 out of 60 (23.33\%) patients had no complications, 4 (6.66\%) patient had wound infection/wound dehiscence, $5(8.33 \%)$ patient had loss of blood and catabolism, $12(20 \%)$ patient had pleural effusion or burst abdomen/ leak, 11 (18.33\%) patient had single organ failure or Mods/Septicemia, and 14 (23.33\%) patient had death.

\section{Similar studies: -}

1]Nabi I, et al. (2016) study shows thatthe postoperative complications are wound infection $18.4 \%$, wound dehiscence 
$3.9 \%$, respiratory complications $10.5 \%$, septicaemia $5.2 \%$, and abdominal collection $3.9 \%$. An anastomosis leak occurred in $2.6 \%$ of patients with typhoid ileal perforation and ileocaecal tuberculosis managed by resection anastomosis in emergency surgery (Table 3). Redo surgery and tension suturing was required in $3.9 \%$ of patients. The overall mortality was $3.9 \%$. Postoperative complications were noticed mostly in those patients who presented late with faecal peritonitis, septicaemia, and associated comorbidity.

2] Manikanta KS, et al. (2016) shows thatComplications occurred in $22(44 \%)$ out of 50 cases. The common complications seen were respiratory tract infections, wound infections, wound dehiscence, and fecal fistula. Out of 50 patients wound infections seen in 19 (38\% of total patients) patients, would dehiscence in $12(24 \%$ of total patients) patients, and respiratory complications in $8(16 \%$ of total patients). Faecal fistulae were seen in 8 ( $16 \%$ of total patients) cases. The highest complication rate was seen with resection anastomosis, out of 17 patients 13 developed complications. The least complication rates were with simple primary closure, out of 33 patients 9 developed complications. Among the 50 patients 6 patients succumbed to death. All the patients who died were undergone resection anastomosis. There was no mortality in the primary simple closure segment. Septicaemia causes $04(66.67 \%)$ patient death, faecal fistula causes $01(1.67 \%)$ patient death and acute respiratory distress syndrome causes 1 ( $1.67 \%)$ patient death. The mortality rate was $12 \%$.

\section{X-CLAVIEN-DINDO CLASSIFICATION}

In our study Using the Clavien-Dindo classification, 14 out of $60(23.33 \%)$ patients had no complications, 4 (6.66\%) had grade I complication, 5 (8.33\%) had grade II complications, 12 (20\%) had grade III complications, 11 (18.33\%) had grade IV complications, and 14 (23.33\%) had grade V complication rates.

\section{Similar studies: -}

1] Singh A, et al. (2016) study shows that Using the Clavien-Dindo classification, 134 out of 350 (38.28\%) patients had no complications, 63 (18\%) had grade I complication, 58 (16.57\%) had grade II complications, 32 (9.14\%) had grade III complications, 25 (7.14\%) had grade IV complications, and 38 (10.85\%) had grade V complication rates Discussion Intestinal perforation is the most dreadful complication in developing countries leading to diffuse peritonitis

\section{SUMMARY}

This was an observational prospective study was carried out in Department of General Surgery, Sri Aurobindo Medical College and P.G. Institute, Indore, which includes total 60 patients of perforation peritonitis admitted and treated in the department, During the period of November 2017 to May 2019. End of the study concludes the following points:

- In my study, most of the cases were between age group 2039(50\%).

- Perforation peritonitis more common in males 41 (68.33\%), male: female ratio being $2.1: 1$.

- Comorbidities were present maximum in age group 40-59 years in $(53.33 \%)$ patients and absent in $(46.66 \%)$ patients. $(66.66 \%)$ patients were discharged in this group and (33.33\%) patients expired.

- In our study Majority of patients presented within 2-3 days from the onset of symptoms $36(60 \%)$.

- Patients who presented after 3 days from onset of symptoms $20(33.33 \%)$ all of them had complications $20(100 \%)$. In this group 7 patient got discharged $7(35 \%)$ and $13(65 \%)$ patients expired. P Value was $<0.001$ which is significant.

- In our study Most common symptoms in patients presenting with perforation is Abdominal pain in 60
(100\%) patients. $45(75 \%)$ patients had constipation \& obstipation, 41 (68.33\%) patients had vomiting, 33(55\%) of patients had fever, 17 (28.33\%) patients had abdominal distensions the other common symptoms.

- Out of 60 patients, all 60(100\%) patients had abdominal tenderness and guarding, $47(78.33 \%)$ patients had absent bowel sounds, 42(70\%) patients had tachycardia, $26(43.33 \%)$ patients had hypotension, 23 (38.33\%) patients had tachypnoea and 21 (35\%) patients had low urinary output.

- In $16(26.6 \%)$ patient's comorbid conditions were present, out of them $12(75 \%)$ patients presented after 3 days of onset of symptoms. $12(75 \%)$ patients were haemodynamically unstable. In this group 07(43.75\%) patients got discharged and $9(56.25 \%)$ patient expired

- In $29(48.33 \%)$ patient size of perforation was more than 1 $\mathrm{cm}$ out of which in $10(32.25 \%)$ patients comorbid condition were present, absent in 19 (65.51\%) patient, complication observed in $28(96.55 \%)$ patient and in only 01 (3.44\%) patient there was no complication. P Value was $<0.001$ which is significant

- In $10(16.66 \%)$ patients multiple perforations were found out of which only $01(10 \%)$ patient is haemodynamically stable and $09(90 \%)$ patients were unstable. Complication occurred in $09(90 \%)$ patients and no complication were only in $01(10 \%)$ patients. In this group $04(40 \%)$ patients got discharged and 6(60\%) patient expired. P Value was 0.001 which is significant.

- In $24(40 \%)$ patients more than $500 \mathrm{ml}$ intraperitoneal collection was found, out of which complications developed in all 24(100\%) patients, haemodynamic unstability was present in $18(75 \%)$ patients, duration of hospital stay was more than 14 days in $14(58.33 \%)$ patients. In this group 11 (45.83\%) patients got discharged and $13(54.16 \%)$ patients expired. Chi Square Value was 42.8 and $P$ Value was $<0.001$ which is significant.

- In our study most common site of perforation was gastric perforation $30(49.18 \%)$ out of which 11 (36\%) patients were managed by Grahm's patch repair, 5 (45\%) patient had better outcome and $6(55 \%)$ patient had worse outcome. Modified Grahm's patch repair in 19 (64\%), 8 (42\%) patient had better outcome and 11 (58\%) patient had worse outcome. Next major group was ileal perforation $23(37.7 \%)$ was managed by primary repair 15 (65.21\%), 6 (40\%) patient had better outcome and $9(60 \%)$ patient had worse outcome. Ileostomy with or without primary repair done in 03 (13.04\%), all 3(100\%) had worse outcome and resection and anastomosis done in $05(21.74 \%)$ patients 2 (40\%) had better outcome and $3(60 \%)$ patients had worse outcome. P valve is significant for gastric and ileal perforation.

- Most common procedure performed was exploratory laparotomy with modified grahm's omental patch repair in 19 (31 \%) patients followed by primary repair in $17(27.86 \%)$ patient for ileal and jejunal perforation, grahm's patch repair done in 11 (18.03\%) patients.

- Complication according to clavien -dindo classification 14 out of 60 (23.33\%) patients had no complications, 4 (6.66\%) had grade I complication, 5 (8.33\%) had grade II complications, 12 (20\%) had grade III complications, 11 (18.33\%) had grade IV complications, and 14 (23.33\%) had grade $\mathrm{V}$ complication rates

\section{CONCLUSION}

Perforation peritonitis is a life-threatening condition and requires urgent hospital care, resuscitation and surgery. Early resuscitation and surgery are required to decrease morbidity and mortality. Management and outcomes of perforation peritonitis depends on various factors such as perioperative and intra operative condition.

Post-operative complications increase due to comorbid 
conditions, size and number of perforations and it also affects the outcome of the patient. It is observed that with the increase in contamination (intraperitoneal collection) morbidity increases.

On the basis of risk stratification in Peritonitis patients its management requires lots of expensive modalities, skill, monitoring and treatment to provide better care to the patient. For the classification of complications, a new system is proposed by Clavien-Dindo which is very helpful during perforation surgery, it is used in all over the world and facilitates in comparisons or evaluation of various surgical outcomes between different centres, therapies or surgeons. Clavien-Dindo classification helps us to distinguish a normal postoperative course and the severity of complications, which allows us to compare postoperative morbidity and evaluate the outcomes. The new classification mainly focuses on the medical perspective, with a major emphasis on the risk, type of anaesthesia and procedures or therapy used to correct $a$ complication.

We therefore recommend the use of clavien-dindo classification of complications. We also recommend a larger study with a bigger sample size for better analysis of claviendindo classification of complications and to confirm the findings of our study.

\section{REFERENCES}

1. Singh A, Porwal R, Gupta HP, Sharma AK, Kumawat G. Determinants of outcome in gastrointestinal perforations with special reference to clavien-dindo classification of surgical complications: Experience of a Single Institute in Central Rajasthan. Arch Int Surg2016;6:170-5.

2. Dindo D, Demartines N, Clavien PA. Classification of surgical complications: A new proposal with evaluation in a cohort of 6336 patients and results of a survey. Ann Surg2004;240:205-13.

3. Clavien PA, Barkun J, de Oliveria ML, Vauthey JN, Dindo D, Schulick RD, et al. The Clavien-Dindo Classification of Surgical Complications: Five-Year Experience. Ann Surg2009;250:187-96.

4. Thomas Genuit "Peritonitis and Abdominal Sepsis" eMedicine Sep.2004; 111. www.emedicine.com

5. Sir Zachary Cope Perforation of a Gastric or Duodenal ulcer: 'Cope's Early Diagnosis of the Acute Abdomen 20th ed .2000; 104-17.

6. Chavez MC, Morgan BD. Acute appendicitis with pneumoperitoneum radiographic d iagnosis\& report of 5 cases. Am Surg 1968;32:604-8.

7. Rucker CR, Midle RE, Nay HR: Pneumoperitoneum secondary to perforated appendicitis, Am Surg 1967; 33:188-90.

8. ArolaMittelstaedt. Gastro intestinal Tract General ultrasound .ArolaMittelstaedt (ed) lst ed 473.

9. Founder RE, Fraser AA. Diagnosis, medical management and complications. In:Haubrich, Shaffner, Berk, Bochus. Gastroenterology 5ed, 1995; 749-89

10. Yeo CJ, Zinner MJ. In : Shackelford's Surgery of the alimentary tract, 4ed , 1995; 64-84.

11. David V, Felicano MD. Do perforated duodenal ulcer need an acid decreasing surgical procedure now that omperazole is available? Surg Clin North Amer 1992: 72:369-377.

12. Boey J, Wong J. Perforated duodenal ulcer. World J Surg 1987 ; 11:319-324

13. Seymour NE. Operations for peptic ulcer and their complications. In Sleisenger\& Fortran's Gastrointestinal and Liver Diseases. Vol 1, 6ed, 1999; 696-710.

14. Leigh S, Hamby ,. Perforated gastric and duodenal ulcer. An analysis of prognostic factors. Am Surgeon 1993; 59:319-323.

15. BoeyJ.. Proximal gastric vagotomy, the preferred operation for perforation in acute duodenal ulcer. Ann Surgery 1988; 208: 169-174.

16. Ralph IG, Smith IF. Long term results after a mental patch repair in duodenal ulcers: 5-10 yrs follow up study. Can J Surg 1991;34: 447-449.

17. Johnston D, Martin I. Surgical treatment of gastric and duodenal ulcer. In :Haubrich: Shaffner : Berk.GastroenterologyBochus. 5ed, 1995; 790-804.

18. Kennedy T. Green WER: Stomal and recurrent ulceration: medical or surgical management? Am J Surg 1980;139: 18-21.

19. Meier DE., Tarpley JL.: Typhoid intestinal perforations in Nigerian children. World J Surg 1998; 22: 319-23.

20. Ameh EA. Comparison of three operations for typhoid perforation 1992; Ann Surg 84: 558-9.

21. Eng k, Ranson JHC, LocalioSA : Resection of the perforated segment: A significant advance in treatment of diverticulitis with free perforation or abscess Am J Surg 1977; 133:67.

22. Gyde S., Prior P.,Dew MJ. Mortality in ulcerative colitis Gastroenterology $1982 ; 83: 465$

23. Mouret P, Francois $Y$, Vignal J, et al: Laparoscopic treatment of perforated peptic ulcer. BrJ Surg 77:1006, 1990

24. De la Rosette, Jean J.M.C.H. et al. Categorisation of complications and validation of the Clavien score for percutaneous nephrolithotomy.Eur Urol. $2012 ; 62(2): 246-55$

25. Nabi, I., Munjewar, C., Ranjan, G. et al. Spectrum of perforation peritonitis at a tertiary healthcare centre: A prospective cohort study of 1908 casesHellenic J Surg 2016; 88:181.

26. Kamble RS, Singh M, Jaiswal Y. Prognostic factors in perforative peritonitis: an observational study. Int Surg J 2016;3:1082-92

27. Abdulhameed MME, Abdulmuthalif A, Vamanaprabhu RR. Clinicopathological evaluation of preoperative findings and outcome of perforation peritonitis. J. Evolution Med. Dent. Sci. 2017;6(29):2338-2345,

28. Jain NK, Jain MG, Maini S, Khobragade V. A study of clinical profile and management of perforation peritonitis in a tertiary health centre located in Central India. Int Surg J 2017;4:981-7.

29. Fontana T, Falco N, Torchia M, Tutino R, Gulotta G. Bowel perforation in Crohn's Disease: correlation between CDAI and Clavien-Dindo scores. G Chir. 2017;38(6):303-312.

30. Wang WG, Babu SR, Wang L, Chen Y, Tian BL, He HB. Use of Clavien-Dindo classification in evaluating complications following pancreatic oduodenectomy in 1,056 cases: A retrospective analysis from one single institution. Oncol Lett. 2018;16(2):2023-2029.

31. Pandey R, Ratan R, Puranik AK, Naidu CS, Galagali A, Mehrotra S, Grading of complication following bowel anastomosis using Clavien-Dindo system: Our experience, International Journal of Scientific research 2018; 7(4):494-97

32. Singh SK, Shukla DK, Singh V. Role and impact of WHO Surgical safety checklist implementation on patient safety, in a tertiary level health care center. Int J Surg Med. 2019; 5(2): 49-54

33. Dr Manikanta K S, Dr Sharangouda C Patil and Dr Mir Md.NoorUl Hassan, A Clinical Study of Prognostic Factors in Typhoid lleal Perforation: in a Tertiary Hospital. SSRG International Journal of Medical Science 2016 ;3(5):1-10

34. Nachiappan M, Litake MM. Scoring Systems for Outcome Prediction of Patients with Perforation Peritonitis. J Clin Diagn Res. 2016;10(3):PC01-PC5.

35. Paryani JJ, Patel V, Rathod G. Etiology of Peritonitis and Factors Predicting the Mortality in Peritonitis. Natl J Community Med 2013; 4(1): 145-8.

36. Mewara BC, Chourashiya BK, Porwal S, et al. A Clinical Study of the Spectrum of Gastro Intestinal Perforation Peritonitis in Rural Southern East Rajasthan. J Univer Surg. 2017;5(2):1-4.

37. Malik P, Yadav BL, Haldeniya K, Anuragi G, Goyal R. A 3 Year Prospective Study of 1400 Cases of Perforation Peritonitis : Asia's Largest Single Centre Study Global Journal of Human-Social Science: I Surgeries and Cardiovascular System 2014;14(3):49-54

38. Jhobta RS, Atri AK, Kaushik R, Sharma R, Jhobta A. Spectrum of perforation peritonitis in India review of 504 consecutive cases. World J Emerg Surg $2006 ; 1: 26$ 